\title{
Mesenchymal Stem Cells as a Potent Cell Source for Bone Regeneration
}

\author{
Elham Zomorodian and Mohamadreza Baghaban Eslaminejad \\ Department of Stem Cell and Developmental Biology, Royan Institute for Stem Cell Biology and Technology, ACECR, \\ 1665659911 Tehran, Iran \\ Correspondence should be addressed to Mohamadreza Baghaban Eslaminejad, eslami@royaninstitute.org
}

Received 24 August 2011; Revised 21 November 2011; Accepted 5 December 2011

Academic Editor: Jan Kramer

Copyright ( 92012 E. Zomorodian and M. Baghaban Eslaminejad. This is an open access article distributed under the Creative Commons Attribution License, which permits unrestricted use, distribution, and reproduction in any medium, provided the original work is properly cited.

\begin{abstract}
While small bone defects heal spontaneously, large bone defects need surgical intervention for bone transplantation. Autologous bone grafts are the best and safest strategy for bone repair. An alternative method is to use allogenic bone graft. Both methods have limitations, particularly when bone defects are of a critical size. In these cases, bone constructs created by tissue engineering technologies are of utmost importance. Cells are one main component in the manufacture of bone construct. A few cell types, including embryonic stem cells (ESCs), adult osteoblast, and adult stem cells, can be used for this purpose. Mesenchymal stem cells (MSCs), as adult stem cells, possess characteristics that make them good candidate for bone repair. This paper discusses different aspects of MSCs that render them an appropriate cell type for clinical use to promote bone regeneration.
\end{abstract}

\section{Introduction}

Bone is a highly specific, dynamic tissue capable of maintaining viability under mechanical stress and external continuous compression. This capability of bone tissue diminishes with increasing age [1]. Furthermore, small bone damage can repair spontaneously without intervention. However, if there is extensive bone damage due to pathologic and traumatic injuries, there will be a need for reconstructive surgery and bone transplantation. In this regard, autologous tissue transplantation would be the best and safest strategy for bone repair. Autologous bone graft is taken from the patient's own iliac crest, ribs, or calvarium. Unfortunately, access to autologous bone graft is limited. Furthermore, obtaining an autograft is associated with morbidity, pain, and infection at the donor site. Because of such disadvantages other alternatives are needed $[2,3]$. Allogenic bone tissue implantation may be chosen to repair large bone defects, but this bone substitute also exhibits several drawbacks, which include the possibility of disease transmission, graft rejection, problems with graft integration and viability at the recipient site [4]. Emergence of modern bone engineering strategies based on osteogenic cells, osteoinductive stimulator, and osteoconductive scaffolds are recognized as potential ways to create biologic tissue substitutes for regenerating large bone defects [5]. The choice of cell sources that can efficiently differentiate into bone tissue is the first, important step during bone engineering. Several cell types can potentially be used as cellular components in bone engineering. These include osteoblast, embryonic, and adult stem cells. Among these candidates, mesenchymal stem cells (MSCs) as adult stem cells possess some characteristics that make them more appropriate for use in promoting bone regeneration.

Historically, the definitive presence of MSCs was discovered about 40 years ago by Friedenstein et al. in bone marrow tissue. They described these cells as mononuclear nonphagocytic cells with fibroblast-like phenotype and colongenic potential capable of adhering to the culture surface in a monolayer culture [6]. Later, it has been shown that MSC-like population were present in a wide range of adult tissues, including trabecular bone [7], synovium [8], adipose tissue [9], skeletal muscle [10], periosteum [11], dermis [12], blood $[13,14]$, deciduous teeth [15], amniotic fluid [16], and umbilical cord blood [17]. Currently, good manufacturing 
practice (GMP) has been developed to produce the cells for use in clinic [18].

It should be mentioned that stem cells are defined by two key characteristics: the ability of multilineage differentiation and the capacity of self-renewal [19]. Of these MSCs possess multilineage differentiation potential but have a limited proliferation capacity since they enter senescence after a few population doubling in culture $[20,21]$. Therefore they cannot be considered true stem cells. For this reason, in related literatures the cells have been referred to as by different terminology as colony-forming unit fibroblasts (CFU-Fs), mesenchymal stromal cells (MSCs), marrow stromal cells (MSCs), marrow progenitor cells (MPCs), and marrow stromal fibroblasts (MSFs) [22-28]. Nowadays, the term mesenchymal stem cells is the dominant term most frequently used by investigators. Here, the specific characteristics that make MSCs promising cells for use in bone regeneration strategies will be discussed.

\section{MSCs Escape Ethical Concerns}

Among candidate cells for bone regeneration, embryonic stem cells (ESCs) possess ethical issues limiting their application in bone regeneration. ESCs are derived from the blastocyst inner cell mass and can be directed toward differentiation into varying cell lineages, including osteoblastic cell lineages under suitable culture conditions [29-32]. To date, multiple studies have been conducted on ESCs osteogenic differentiation in vitro and their application in bone tissue engineering with varying scaffolds. For example, it has been shown that culturing ESCs on poly-lactide-co-glycolic (PLGA) or nanofibers made from PLLA (poly (l-lactic acid)) is associated with high expressions of osteogenic markers, including alkaline phosphatase and osteocalcin [33, 34]. Despite increasing interest in the application of ESCs in bone engineering technology, research is highly limited due to political issues as well as ethical concerns associated with these cells. The primary concern is the source from which these cells are derived. The use of excess embryos produced in IVF to create ESCs is not acceptable according to religious and ethical points of view. Additionally, some reports have indicated that transplantation of ESCs has led to teratoma formation in the animal model $[35,36]$. For these reasons postnatal adult stem cells, including MSCs that could be derived from a patient's own tissues and do not possess ethical limitations, are considered more appropriate for clinical use.

\section{MSCs Are Residents of Multiple Tissues}

MSCs have been reported to constitute about 0.01\%-0.001\% of the marrow mononuclear population [37]. These cells can be isolated from marrow aspirates of the superior iliac crest, femur, and tibia. For this purpose, marrow cells are usually enriched for mononuclear cells with Ficoll or Percol and then plated on culture plastic vessels in order to prepare adherent cell populations [38]. It has recently been demonstrated that late plastic adherent MSCs possess higher osteogenic potential [39]. Alternatively, MSCs can be obtained by the preparation of a population positive for STRO-1 or CD105. It has been reported that a population negative for CD45 or Gly-A are from MSCs [40]. By now, many researchers have studied optimized culture and differentiation of MSCs in vitro and their application in regenerating bone defects in animal models and humans [41-44]. Since collection of bone marrow is invasive and expansion and osteogenic differentiation of marrow-derived MSC seem to be reduced with advancing age, investigators have attempted to find other tissue sources for MSCs [45]. According to research, multiple tissues have been found to contain MSC-like population; of these, adipose tissue as well as birth-associated tissues, including umbilical cord and dental pulp, has gained considerable attention.

The presence of cells with multipotent differentiation capacity in adipose tissue is promising due to the ease of accessibility of adipose tissue and its abundance in the body. Adipose tissue can be an appropriate substitute for marrow in regenerative medicine and tissue engineering [46, 47]. Adipose-derived stromal cells (ADSCs) can be derived from adipose collected by liposuction and lipectomy [48]. ADSCs are able to maintain proliferation potential as well as differentiation capacity even in older people. The differentiation potential of ADSCs is largely dependent on the concentration of ascorbic acid and dexamethasone in culture medium $[49,50]$. By now, many studies conducted on animal models have confirmed the regenerative potential of ADSCs in bone defects. The first report regarding repair and production of bone tissue in vivo belongs to Lee et al. who transplanted ADSCs loaded onto PLGA [51]. Later, Hicok et al. have noted the production of osteoid matrix when a combination of ADSCs, hydroxyapatite (HA) and tricalcium phosphate (TCP), were transplanted in nude mice [52]. In 2004, these cells were used for the repair of human calvarial defects [53]. To date the effect of various biomaterials, including HA, human cancellous bone fragments, deproteinized bovine bone granules, and titanium, has been investigated in terms of ADSC attachment, proliferation, and differentiation [54, 55].

The umbilical cord from a newborn baby contains two arteries and a vein covered with mucus connective tissue rich in hyaluronic acid, referred to as Wharton's jelly. According to studies, MSC-like cells can be derived from various components of this cord [56]. For example, blood from an umbilical cord is a rich source for pluripotent cells which are also referred to as umbilical-cord-blood-derived MSCs (UCB-MSCs). These cells are quite similar to marrowderived MSCs and have osteogenic potential in an optimized culture [57-59]. Many investigations have thus far been conducted on bone engineering by using these cells and various scaffolds $[60,61]$.

Several stem cell types in dental tissue have been reported including dental pulp stem cells (DPSCs), stem cells from human exfoliated deciduous teeth (SHED), stem cells of the apical papilla (SCAP), periodontal ligament stem cells (PDLSCs), and dental follicle progenitor cells (DFPCs) $[15,62]$. Since DPSCs can be easily isolated by enzymatic digestion of pulp tissue many studies have been conducted 
regarding bone engineering with these cells and appropriate 3D scaffolds, including HA/TCP and polylactic-co-glycolic acid (PLGA) [63, 64].

\section{MSCs Can Efficiently Differentiate along an Osteogenic Lineage}

MSCs osteogenic property was the first reported differentiation capacity when they were discovered. Indeed, even prior to definitive isolation of MSCs from bone marrow, some transplantation experiments clearly showed the osteogenic capacity of marrow tissue. Friedenstein et al. were the first to isolate and describe the cellular equivalent of osteogenic features of marrow tissue [65].

Osteogenic differentiation is a highly programmed process that consists of many stages including proliferation, differentiation, matrix deposition, mineralization, and matrix maturation. The general protocol for in vitro bone differentiation of MSCs involves incubation of cell monolayer in a culture medium containing dexamethasone, beta glycerol phosphate, and ascorbic acid for a period of two to three weeks [66]. Dexamethasone is a synthetic glucocorticoid that stimulates MSC proliferation and is essential for their osteogenic differentiation $[67,68]$. Although the mechanism of dexamethasone's effect is not well known, it has been speculated that this reagent exerts its effects through upregulation of the beta catenin-like molecule TAZ, which results in up-regulation of Runx2-related transcription factor and osteogenic differentiation [69]. The optimal concentration of this reagent for MSC bone differentiation is about $10 \mathrm{nM}$, which corresponds with its physiologic concentrations [70]. Organic phosphate released after enzymatic hydrolysis of beta glycerol phosphate plays an important role in matrix mineralization. This free phosphate is usually applied in 5$10 \mathrm{mM}$ concentrations for MSC bone differentiation [71]. Ascorbic acid is a cofactor in the hydroxylation of prolins and lysine moiety of collagen molecules and is the abundant protein in ECM. This reagent is used in $50-500 \mu \mathrm{M}$ concentrations [72]. In addition to these osteogenic supplements, there are other osteogenic factors including (1,25-D3) 1,25dihydroxyvitamin and BMPs (BMP2) [73].

MSC in vitro bone differentiation results from the activation of some well-known molecular signaling pathways. Each osteogenic reagent activates a molecular pathway that leads to a differentiated phenotype. Although the osteogenic effects of a number of these reagents have long been known, specific pathways by which the effects are mediated remain to be clarified. The activation of wingless-type MMTV integration site family of the protein (Wnt) signaling pathway [74], mitogen-activated protein kinase (MAPK) signaling pathway [75], TGF beta and BMP signaling pathways [76], and RHOGTPase signaling pathway [77] has been established in MSC bone differentiation.

Activation of signaling pathways by osteogenic supplements eventually leads to activation of osteoblast-specific signal proteins and specific osteoblastic transcription factors. Cbfa1 (core binding factor alpha 1) also called as Runx2 (runt-related gene 2) is one of the most studied transcription factors expressed in MSCs upon their commitment toward osteogenic differentiation $[78,79]$. Runx2, as a master switch, adheres to osteoblast-specific cis-acting element (OSE2) in the gene promoter region stimulating the expression of bonespecific genes such as coll I, osteocalcin, osteopontin, and alkaline phosphatase [80]. Osterix is another transcription factor involved in MSC bone differentiation, which has been clearly shown in murine MSCs where they were retrovirally transduced with the osterix gene [81]. Addition of dexamethasone to the culture of murine calvarial osteoblasts has been reported to induce expression of osterix as well as Runx2 genes [82].

Optimal conditions for MSC in vitro bone differentiation are well been established. For example, the addition of rhBMP-2 to osteogenic medium can facilitate proliferation and osteogenic differentiation of BMSCs both in vitro and in vivo. The use of alpha MEM versus DMEM and application of low-passaged versus high-passaged cells can end with higher expression of osteogenic genes and more culture mineralization [83-85]. Studies on scaffold designing and the effect of biomaterial on bone repair have indicated that calcium phosphate-based scaffolds, including hydroxyapatite (HA) and tricalcium phosphate (TCP), are more appropriate for bone engineering due to their osteoconductive properties [86]. Applying fluid shear stress (FSS) on the MSC osteogenic culture increases the expression of bone-specific genes and deposition of mineralized matrix. FSS mediates its effects through regulation of mechanosensitive signaling molecules, including ion channel and integrins, which are able to convert mechanical into chemical signals $[87,88]$.

\section{Nonimmunogenic Properties of MSCs}

MSCs possess immunologically specific characteristics; therefore they would be general donors for therapeutic applications. Immunologic phenotypes of MSCs are MHC I+, MHC II-, CD 40-, CD80-, and CD 86- [89]. Graft rejection by the immune system occurs when $\mathrm{T}$ cells are fully activated. T cells require two signals to become fully activated. The first signal is provided through the T-cell receptor which interacts with peptide-MHC molecule 1 on the membrane of antigen-presenting cells (APC). A second signal, the costimulatory signal, is provided by the interaction between co-stimulatory molecules, including CD80 and CD86 that are expressed on the membrane of APC and the T cell [90]. MSCs do not trigger T-cell activation owing to the absence of CD80 and CD86 in their membrane [91]. The immunosuppressive nature of MSCs has been shown in skin allografts of baboon models.

According to research, MSCs secrete soluble factors that inhibit CD4+ and CD8+ T-cell activation as well as proliferation. Among these factors are indoleamine 2,3-dioxygenase (IDO), nitric oxide, TGF-beta, and prostaglandin E 2 [9295]. It has been demonstrated that MSCs stop the B-cell cycle at the G0/G1 stage and inhibit their differentiation into plasma cells $[96,97]$. Ramasamy et al. have indicated that BMSCs are able to inhibit dendritic cell (DC) differentiation and prevent them from entering into the cell cycle [98]. 
DCs are able to efficiently present antigens to lymphocytes. According to research, monocytes differentiate into DCs in the presence of MSCs [99].

Immunomodulatory features of MSCs make them an important cellular candidate for cell-based treatment of tissue defects in an allogenic setting. For this reason, there is hope that MSCs could replace autologous and allogenic bone grafts which have known exhibited limitations in terms of availability and risk of pathogen transmission, respectively. At the allogenic approach, it will be possible to develop a cell bank to maintain MSCs from every donor for use in cell therapy. Prior to routine application of the cells in the clinic, an exact understanding of the immunologic features of MSCs and the underlying mechanism of action is needed $[100,101]$.

\section{Injury-Seeking Capability of MSCs}

One of the most important capabilities of MSCs is their migration capacity in response to signals produced by an injured bone $[102,103]$. At the injury site, MSCs could possibly help with repair in two ways: (1) they differentiate to tissue cells in order to restore lost morphology as well as function, and (2) MSCs secrete a wide spectrum of bioactive factors that help to create a repair environment by possessing antiapoptotic effects, immunoregulatory function, and the stimulation of endothelial progenitor cell proliferation [103].

The precise mechanisms of cell trafficking in blood, transmigration through endothelial cell, and homing to the injured site are not thoroughly understood, but it has been speculated that chemokines and their receptors regulate this process [89]. Chemokines (chemotactic cytokines) are small proteins (8-10 KDs) with a capacity for creating a chemical environment appropriate for the migration of lymphocytes, neutrophils, and other immune cells towards inflammation, angiogenesis, and the organogenesis site. On the other hand, MSCs express a series of chemokine receptors that play a role in their migration in response to a chemokine gradient produced at the damaged site. These chemokine receptors include CCR1, CCR7, CCR9, CCR3, CCR4, CCR5, and CX3CR1 [104]. CXCR4 receptor and its specific chemokine (stromal cell-derived factor 1 (SDF1)) play an important role in stem cell trafficking, particularly HSCs [105]. It has been proposed that SDF1/CXCR4 could be a homing signal for MSCs in bone repair.

Kitaori et al. have reported that SDF1 expressed by periosteum mediates bone repair in the murine femoral model by recruiting MSCs to the fracture site [106]. The SDF1 gradient causes both host as well as infused MSCs to migrate towards the injured area. MSC migration has been proven in clinical trials performed by Horwitz et al. in which MSCs were injected to regenerate bone in six patients who suffered from osteogenesis imperfecta, where osteoblasts secrete defective collagen I resulting in osteopenia. Observations indicated that in 5 out of 6 children who received allogenic MSCs, cell migration to various tissues that included bone, skin, and marrow stroma was observed [107]. Transplantation of MSCs was followed by increased formation of compact bone and reduction in fracture frequency.

Considering the relationships of cell migration with the chemokine concentration gradient, it can be concluded that the application of MSCs must be performed at the time when the chemokine concentration gradient is established at an adjacent area to the injured site.

\section{MSCs as Vehicles for Bone Gene Therapy}

MSCs could be ideal carriers for therapeutic genes at a cell-mediated gene delivery strategy owing to their unique characteristics that include ease of isolation, culture, and expansion as well as their immunomodulatory property [108].

In the normal process of bone development and repair, cytokines and osteoinductive growth factors play a major role by recruiting osteogenic progenitors at the bone formation site and promoting their differentiation into bone cell lineages [109]. Therefore, the application of such factors which include related recombinant growth factors in large areas of bone damage would enhance new bone formation. However the problem is that recombinant growth factors have a limited half-life that limits their sustained supply into damaged tissue. To overcome this limitation, gene transfer strategies using cellular carriers have been proposed. This strategy offers the sustained delivery of the osteogenic factor to the damaged area [110]. Genetic manipulation of MSCs can be achieved by transduction using viral vectors such as the adenovirus (Ad) [111] or transfection by nonviral vectors such as liposomes [112]. Viral vectors have the advantage of high efficiency but trigger the immune system. In addition, they possess varying capacity to transfer genes into dividing and nondividing cells [113]. Non-viral vectors possess the advantage of not being toxic [114].

Many investigators have tried to regenerate bone by transfecting MSCs with the BMP gene. For example, Lieberman et al. have indicated that autologous BMSCs expressing Ad-BMP2 can considerably promote segmental femoral defects in rat models when compared with BMSCs expressing Ad-LacZ [115]. Transplantation of Ad-BMP2MSCs in rabbits has been reported to be associated with new bone formation [116]. In spite of the multiple studies that have focused on temporary expression of factors using the adenovirus vector, Gysin et al. have observed permanent expression of BMP4 using retrovirus in BMSCs which lead to repair of critical sized calvarial defects in rats [117]. In one study, Lin et al. have compared BMP4-transfected MSCs from marrow and adipose tissue in bone repair of a rabbit model and found no significant difference [118].

It has been shown that Ad-Runx2-MSCs transplanted in murine calvarial defects produce more bone tissue compared to MSCs [119]. Recent studies have focused on simultaneous application of BMPs and RUNX2. When these two factors were entered into an immortal MSCs line and injected into mice, considerable bony ossicle with marrow cavity was observed (compared to the application of cells that expressed Ad-BMP2) [120]. Although no clinical trial to date has been conducted using genetically modified MSCs, studies have 
indicated that such a strategy would be more effective in enhancing bone repair.

\section{Conclusion}

MSCs as adult stem cells are free from ethical concerns, residents of multiple tissues, able to efficiently differentiate along an osteogenic lineage, possess non-immunogenic properties, have injury-seeking capabilities, and can be used as vehicles for bone gene therapy. These characteristics make MSCs safe and promising candidates for use in bone engineering and regeneration. Currently, several clinical trials are being performed on problematic human bone lesions, including nonunion fractures, delayed union, bone cysts, and bone neoplasms, among others. These ongoing registered trials are available at the following clinical trial website: http://clinicaltrials.gov/.

\section{Conflict of Interests}

None of the authors have conflict of interests to declare.

\section{References}

[1] M. Mehta, P. Strube, A. Peters et al., "Influences of age and mechanical stability on volume, microstructure, and mineralization of the fracture callus during bone healing: is osteoclast activity the key to age-related impaired healing?" Bone, vol. 47, no. 2, pp. 219-228, 2010.

[2] C. R. Perry, "Bone repair techniques, bone graft, and bone graft substitutes," Clinical Orthopaedics and Related Research, no. 360, pp. 71-86, 1999.

[3] R. F. Heary, R. P. Schlenk, T. A. Sacchieri et al., "Persistent iliac crest donor site pain: independent outcome assessment," Neurosurgery, vol. 50, no. 3, pp. 510-517, 2002.

[4] A. Catanzariti and L. Karlock, "The application of allograft bone in foot and ankle surgery," Journal of Foot and Ankle Surgery, vol. 35, no. 5, pp. 440-451, 1996.

[5] M. D. Kwan and M. T. Longaker, "Regenerative medicine: the next frontier," Transplantation, vol. 86, no. 2, pp. 206-207, 2008.

[6] A. J. Friedenstein, R. K. Chailakhjan, and K. S. Lalykina, "The development of fibroblast colonies in monolayer cultures of guinea-pig bone marrow and spleen cells," Cell and Tissue Kinetics, vol. 3, no. 4, pp. 393-403, 1970.

[7] U. Nöth, A. M. Osyczka, R. Tuli, N. J. Hickok, K. G. Danielson, and R. S. Tuan, "Multilineage mesenchymal differentiation potential of human trabecular bone-derived cells," Journal of Orthopaedic Research, vol. 20, no. 5, pp. 1060-1069, 2002.

[8] C. De Bari, F. Dell'Accio, P. Tylzanowski, and F. P. Luyten, "Multipotent mesenchymal stem cells from adult human synovial membrane," Arthritis and Rheumatism, vol. 44, no. 8, pp. 1928-1942, 2001.

[9] P. A. Zuk, M. Zhu, H. Mizuno et al., "Multilineage cells from human adipose tissue: implications for cell-based therapies," Tissue Engineering, vol. 7, no. 2, pp. 211-228, 2001.

[10] P. Bosch, D. S. Musgrave, J. Y. Lee et al., "Osteoprogenitor cells within skeletal muscle," Journal of Orthopaedic Research, vol. 18, no. 6, pp. 933-944, 2000.
[11] H. Nakahara, V. M. Goldberg, and A. I. Caplan, "Cultureexpanded human periosteal-derived cells exhibit osteochondral potential in vivo," Journal of Orthopaedic Research, vol. 9, no. 4, pp. 465-476, 1991.

[12] H. E. Young, T. A. Steele, R. A. Bray et al., "Human reserve pluripotent mesenchymal stem cells are present in the connective tissues of skeletal muscle and dermis derived from fetal, adult, and geriatric donors," Anatomical Record, vol. 264, no. 1, pp. 51-62, 2001.

[13] N. J. Zvaifler, L. Marinova-Mutafchieva, G. Adams et al., "Mesenchymal precursor cells in the blood of normal individuals," Arthritis Research, vol. 2, no. 6, pp. 477-488, 2000.

[14] Q. He, C. Wan, and G. Li, "Concise review: multipotent mesenchymal stromal cells in blood," Stem Cells, vol. 25, no. 1, pp. 69-77, 2007.

[15] G. T. J. Huang, S. Gronthos, and S. Shi, "Critical reviews in oral biology \& medicine: mesenchymal stem cells derived from dental tissues vs. those from other sources: their biology and role in regenerative medicine," Journal of Dental Research, vol. 88, no. 9, pp. 792-806, 2009.

[16] M. B. Eslaminejad, S. Jahangir, and N. Aghdami, "Mesenchymal stem cells from murine amniotic fluid as a model for preclinical investigation," Archives of Iranian Medicine, vol. 14, no. 2, pp. 96-103, 2011.

[17] S. Karahuseyinoglu, O. Cinar, E. Kilic et al., "Biology of stem cells in human umbilical cord stroma: In situ and in vitro surveys," Stem Cells, vol. 25, no. 2, pp. 319-331, 2007.

[18] L. Sensebé, P. Bourin, and K. Tarte, "Good manufacturing practices production of mesenchymal stem/stromal cells," Human Gene Therapy, vol. 22, no. 1, pp. 19-26, 2011.

[19] H. M. Blau, T. R. Brazelton, and J. M. Weimann, "The evolving concept of a stem cell: entity or function?” Cell, vol. 105, no. 7, pp. 829-841, 2001.

[20] M. M. Bonab, K. Alimoghaddam, F. Talebian, S. H. Ghaffari, A. Ghavamzadeh, and B. Nikbin, "Aging of mesenchymal stem cell in vitro," BMC Cell Biology, vol. 7, article no. 14, 2006.

[21] K. Stenderup, J. Justesen, C. Clausen, and M. Kassem, "Aging is associated with decreased maximal life span and accelerated senescence of bone marrow stromal cells," Bone, vol. 33, no. 6, pp. 919-926, 2003.

[22] A. Keating, "Mesenchymal stromal cells," Current Opinion in Hematology, vol. 13, no. 6, pp. 419-425, 2006.

[23] A. H. Piersma, K. G. M. Brockbank, and R. E. Ploemacher, "Characterization of fibroblastic stromal cells from murine bone marrow," Experimental Hematology, vol. 13, no. 4, pp. 237-243, 1985.

[24] A. I. Caplan, "The mesengenic process," Clinics in Plastic Surgery, vol. 21, no. 3, pp. 429-435, 1994.

[25] S. P. Bruder, N. Jaiswal, and S. E. Haynesworth, "Growth kinetics, self-renewal, and the osteogenic potential of purified human mesenchymal stem cells during extensive subcultivation and following cryopreservation," Journal of Cellular Biochemistry, vol. 64, no. 2, pp. 278-294, 1997.

[26] D. J. Prockop, "Marrow stromal cells as stem cells for nonhematopoietic tissues," Science, vol. 276, no. 5309, pp. 71-74, 1997.

[27] G. Ferrari, G. Cusella-De Angelis, M. Coletta et al., "Muscle regeneration by bone marrow-derived myogenic progenitors," Science, vol. 279, no. 5356, pp. 1528-1530, 1998.

[28] P. A. Conget and J. J. Minguell, "Phenotypical and functional properties of human bone marrow mesenchymal progenitor cells," Journal of Cellular Physiology, vol. 181, no. 1, pp. 67-73, 1999. 
[29] E. J. Robertson, "Derivation and maintenance of embryonic stem cell cultures," Methods in Molecular Biology, vol. 75, pp. 173-184, 1997.

[30] N. L. Woll, J. D. Heaney, and S. K. Bronson, "Osteogenic nodule formation from single embryonic stem cell-derived progenitors," Stem Cells and Development, vol. 15, no. 6, pp. 865-879, 2006.

[31] L. D. K. Buttery, S. Bourne, J. D. Xynos et al., "Differentiation of osteoblasts and in vitro bone formation from murine embryonic stem cells," Tissue Engineering, vol. 7, no. 1, pp. 89-99, 2001.

[32] C. Hegert, J. Kramer, G. Hargus et al., "Differentiation plasticity of chondrocytes derived from mouse embryonic stem cells," Journal of Cell Science, vol. 115, no. 23, pp. 46174628, 2002.

[33] X. F. Tian, B. C. Heng, Z. Ge et al., "Comparison of osteogenesis of human embryonic stem cells within 2D and 3D culture systems," Scandinavian Journal of Clinical and Laboratory Investigation, vol. 68, no. 1, pp. 58-67, 2008.

[34] L. A. Smith, X. Liu, J. Hu, and P. X. Ma, "The influence of three-dimensional nanofibrous scaffolds on the osteogenic differentiation of embryonic stem cells," Biomaterials, vol. 30, no. 13, pp. 2516-2522, 2009.

[35] A. S. Daar, A. Bhatt, E. Court, and P. A. Singer, "Stem cell research and transplantation: science leading ethics," Transplantation Proceedings, vol. 36, no. 8, pp. 2504-2506, 2004.

[36] P. S. Knoepfler, "Deconstructing stem cell tumorigenicity: a roadmap to safe regenerative medicine," Stem Cells, vol. 27, no. 5, pp. 1050-1056, 2009.

[37] M. F. Pittenger, A. M. Mackay, S. C. Beck et al., "Multilineage potential of adult human mesenchymal stem cells," Science, vol. 284, no. 5411, pp. 143-147, 1999.

[38] M. B. Eslaminejad, A. Nikmahzar, L. Taghiyar, S. Nadri, and M. Massumi, "Murine mesenchymal stem cells isolated by low density primary culture system," Development Growth and Differentiation, vol. 48, no. 6, pp. 361-370, 2006.

[39] E. Leonardi, G. Ciapetti, S. R. Baglìo, V. Devescovi, N. Baldini, and D. Granchi, "Osteogenic properties of late adherent subpopulations of human bone marrow stromal cells," Histochemistry and Cell Biology, vol. 132, no. 5, pp. 547-557, 2009.

[40] J. M. Seong, B. C. Kim, J. H. Park, I. K. Kwon, A. Mantalaris, and Y. S. Hwang, "Stem cells in bone tissue engineering," Biomedical Materials, vol. 5, no. 6, Article ID 062001, 2010.

[41] Q. Shang, Z. Wang, W. Liu, Y. Shi, L. Cui, and Y. Cao, "Tissue-engineered bone repair of sheep cranial defects with autologous bone marrow stromal cells," Journal of Craniofacial Surgery, vol. 12, no. 6, pp. 586-593, 2001.

[42] E. Kon, A. Muraglia, A. Corsi et al., "Autologous bone marrow stromal cells loaded onto porous hydroxyapatite ceramic accelerate bone repair in critical-size defects of sheep long bones," Journal of Biomedical Materials Research, vol. 49, no. 3, pp. 328-337, 2000.

[43] R. Quarto, M. Mastrogiacomo, R. Cancedda et al., "Repair of large bone defects with the use of autologous bone marrow stromal cells," New England Journal of Medicine, vol. 344, no. 5, pp. 385-386, 2001.

[44] T. Morishita, K. Honoki, H. Ohgushi, N. Kotobuki, A. Matsushima, and Y. Takakura, "Tissue engineering approach to the treatment of bone tumors: three cases of cultured bone grafts derived from patients' mesenchymal stem cells," Artificial Organs, vol. 30, no. 2, pp. 115-118, 2006.
[45] S. Zhou, J. S. Greenberger, M. W. Epperly et al., "Age-related intrinsic changes in human bone-marrow-derived mesenchymal stem cells and their differentiation to osteoblasts," Aging Cell, vol. 7, no. 3, pp. 335-343, 2008.

[46] N. Yamamoto, H. Akamatsu, S. Hasegawa et al., "Isolation of multipotent stem cells from mouse adipose tissue," Journal of Dermatological Science, vol. 48, no. 1, pp. 43-52, 2007.

[47] C. Q. Qu, G. H. Zhang, L. J. Zhang, and G. S. Yang, "Osteogenic and adipogenic potential of porcine adipose mesenchymal stem cells," In Vitro Cellular and Developmental Biology. Animal, vol. 43, no. 2, pp. 95-100, 2007.

[48] B. A. Bunnell, M. Flaat, C. Gagliardi, B. Patel, and C. Ripoll, "Adipose-derived stem cells: isolation, expansion and differentiation," Methods, vol. 45, no. 2, pp. 115-120, 2008.

[49] D. A. De Ugarte, K. Morizono, A. Elbarbary et al., "Comparison of multi-lineage cells from human adipose tissue and bone marrow," Cells Tissues Organs, vol. 174, no. 3, pp. 101109, 2003.

[50] L. de Girolamo, M. F. Sartori, W. Albisetti, and A. T. Brini, "Osteogenic differentiation of human adipose-derived stem cells: comparison of two different inductive media," Journal of Tissue Engineering and Regenerative Medicine, vol. 1, no. 2, pp. 154-157, 2007.

[51] J. A. Lee, B. M. Parrett, J. A. Conejero et al., "Biological alchemy: engineering bone and fat from fat-derived stem cells," Annals of Plastic Surgery, vol. 50, no. 6, pp. 610-617, 2003.

[52] K. C. Hicok, T. V. Du Laney, Y. S. Zhou et al., "Human adipose-derived adult stem cells produce osteoid in vivo," Tissue Engineering, vol. 10, no. 3-4, pp. 371-380, 2004.

[53] S. Lendeckel, A. Jödicke, P. Christophis et al., "Autologous stem cells (adipose) and fibrin glue used to treat widespread traumatic calvarial defects: case report," Journal of CranioMaxillofacial Surgery, vol. 32, no. 6, pp. 370-373, 2004.

[54] L. De Girolamo, M. F. Sartori, E. Arrigoni et al., "Human adipose-derived stem cells as future tools in tissue regeneration: osteogenic differentiation and cell-scaffold interaction," International Journal of Artificial Organs, vol. 31, no. 6, pp. 467-479, 2008.

[55] I. Tognarini, S. Sorace, R. Zonefrati et al., "In vitro differentiation of human mesenchymal stem cells on Ti6Al4V surfaces," Biomaterials, vol. 29, no. 7, pp. 809-824, 2008.

[56] A. Hilfiker, C. Kasper, R. Hass, and A. Haverich, "Mesenchymal stem cells and progenitor cells in connective tissue engineering and regenerative medicine: is there a future for transplantation?" Langenbeck's Archives of Surgery, vol. 396, no. 4, pp. 489-497, 2011.

[57] D. T. Covas, J. L. C. Siufi, A. R. L. Silva, and M. D. Orellana, "Isolation and culture of umbilical vein mesenchymal stem cells," Brazilian Journal of Medical and Biological Research, vol. 36, no. 9, pp. 1179-1183, 2003.

[58] C. Rosada, J. Justesen, D. Melsvik, P. Ebbesen, and M. Kassem, "The human umbilical cord blood: a potential source for osteoblast progenitor cells," Calcified Tissue International, vol. 72, no. 2, pp. 135-142, 2003.

[59] E. L. Hutson, S. Boyer, and P. G. Genever, "Rapid isolation, expansion, and differentiation of osteoprogenitors from fullterm umbilical cord blood," Tissue Engineering, vol. 11, no. 9-10, pp. 1407-1420, 2005.

[60] D. Yinze, Q. Ma, F. Cui, and Y. Zhong, "Human umbilical cord mesenchymal stem cells: osteogenesis in vivo as seed cells for bone tissue engineering," Journal of Biomedical Materials Research A, vol. 91, no. 1, pp. 123-131, 2009. 
[61] B. J. Jang, Y. E. Byeon, J. H. Lim et al., "Implantation of canine umbilical cord blood-derived mesenchymal stem cells mixed with beta-tricalcium phosphate enhances osteogenesis in bone defect model dogs," Journal of Veterinary Science, vol. 9, no. 4, pp. 389-395, 2008.

[62] S. Nakamura, Y. Yamada, W. Katagiri, T. Sugito, K. Ito, and M. Ueda, "Stem cell proliferation pathways comparison between human exfoliated deciduous teeth and dental pulp stem cells by gene expression profile from promising dental pulp," Journal of Endodontics, vol. 35, no. 11, pp. 1536-1542, 2009.

[63] G. Laino, F. Carinci, A. Graziano et al., "In vitro bone production using stem cells derived from human dental pulp," Journal of Craniofacial Surgery, vol. 17, no. 3, pp. 511515, 2006.

[64] R. d'Aquino, G. Papaccio, G. Laino, and A. Graziano, "Dental pulp stem cells: a promising tool for bone regeneration," Stem Cell Reviews, vol. 4, no. 1, pp. 21-26, 2008.

[65] A. J. Friedenstein, I. I. Piatetzky-Shapiro, and K. V. Petrakova, "Osteogenesis in transplants of bone marrow cells," Journal of Embryology and Experimental Morphology, vol. 16, no. 3, pp. 381-390, 1966.

[66] M. B. Eslaminejad and L. Taghiyar, "Study of the structure of canine mesenchymal stem cell osteogenic culture," Journal of Veterinary Medicine Series C, vol. 39, no. 5, pp. 446-455, 2010.

[67] C. G. Bellows, J. N. M. Heersche, and J. E. Aubin, "Determination of the capacity for proliferation and differentiation of osteoprogenitor cells in the presence and absence of dexamethasone," Developmental Biology, vol. 140, no. 1, pp. 132-138, 1990.

[68] P. S. Leboy, J. N. Beresford, C. Devlin, and M. E. Owen, "Dexamethasone induction of osteoblast mRNAs in rat marrow stromal cell cultures," Journal of Cellular Physiology, vol. 146, no. 3, pp. 370-378, 1991.

[69] D. Hong, H. X. Chen, Y. Xue et al., "Osteoblastogenic effects of dexamethasone through upregulation of TAZ expression in rat mesenchymal stem cells," Journal of Steroid Biochemistry and Molecular Biology, vol. 116, no. 1-2, pp. 8692, 2009.

[70] S. Walsh, G. R. Jordan, C. Jefferiss, K. Stewart, and J. N. Beresford, "High concentrations of dexamethasone suppress the proliferation but not the differentiation or further maturation of human osteoblast precursors in vitro: relevance to glucocorticoid-induced osteoporosis," Rheumatology, vol. 40, no. 1, pp. 74-83, 2001.

[71] G. R. Beck Jr., B. Zerler, and E. Moran, "Phosphate is a specific signal for induction of osteopontin gene expression," Proceedings of the National Academy of Sciences of the United States of America, vol. 97, no. 15, pp. 8352-8357, 2000.

[72] C. Vater, P. Kasten, and M. Stiehler, "Culture media for the differentiation of mesenchymal stromal cells," Acta Biomaterialia, vol. 7, no. 2, pp. 463-477, 2011.

[73] P. Lui, B. O. Oyajobi, R. G. G. Russell, and A. Scutt, "Regulation of osteogenic differentiation of human bone marrow stromal cells: interaction between transforming growth factor- $\beta$ and $1,25(\mathrm{OH}) 2$ vitamin D3 in vitro," Calcified Tissue International, vol. 65, no. 2, pp. 173-180, 1999.

[74] C. N. Bennett, K. A. Longo, W. S. Wright et al., "Regulation of osteoblastogenesis and bone mass by Wnt10b," Proceedings of the National Academy of Sciences of the United States of America, vol. 102, no. 9, pp. 3324-3329, 2005.
[75] R. K. Jaiswal, N. Jaiswal, S. P. Bruder, G. Mbalaviele, D. R. Marshak, and M. F. Pittenger, "Adult human mesenchymal stem cell differentiation to the osteogenic or adipogenic lineage is regulated by mitogen-activated protein kinase," Journal of Biological Chemistry, vol. 275, no. 13, pp. 96459652, 2000.

[76] J. Massagué and D. Wotton, "Transcriptional control by the TGF- $\beta /$ Smad signaling system," EMBO Journal, vol. 19 , no. 8, pp. 1745-1754, 2000.

[77] V. E. Meyers, M. Zayzafoon, J. T. Douglas, and J. M. McDonald, "RhoA and cytoskeletal disruption mediate reduced osteoblastogenesis and enhanced adipogenesis of human mesenchymal stem cells in modeled microgravity," Journal of Bone and Mineral Research, vol. 20, no. 10, pp. 1858-1866, 2005.

[78] A. Yamaguchi, T. Komori, and T. Suda, "Regulation of osteoblast differentiation mediated by bone morphogenetic proteins, hedgehogs, and Cbfal," Endocrine Reviews, vol. 21, no. 4, pp. 393-411, 2000.

[79] P. Ducy, "Cbfa1: a molecular switch in osteoblast biology," Developmental Dynamics, vol. 219, no. 4, pp. 461-471, 2000.

[80] R. T. Franceschi and G. Xiao, "Regulation of the osteoblastspecific transcription factor, Runx2: Responsiveness to multiple signal transduction pathways," Journal of Cellular Biochemistry, vol. 88, no. 3, pp. 446-454, 2003.

[81] Q. Tu, P. Valverde, and J. Chen, "Osterix enhances proliferation and osteogenic potential of bone marrow stromal cells," Biochemical and Biophysical Research Communications, vol. 341, no. 4, pp. 1257-1265, 2006.

[82] M. Igarashi, N. Kamiya, M. Hasegawa, T. Kasuya, T. Takahashi, and M. Takagi, "Inductive effects of dexamethasone on the gene expression of Cbfa1, Osterix and bone matrix proteins during differentiation of cultured primary rat osteoblasts," Journal of Molecular Histology, vol. 35, no. 1, pp. 3-10, 2004.

[83] H. Yamagiwa, N. Endo, K. Tokunaga, T. Hayami, H. Hatano, and H. E. Takahashi, "In vivo bone-forming capacity of human bone marrow-derived stromal cells is stimulated by recombinant human bone morphogenetic protein-2," Journal of Bone and Mineral Metabolism, vol. 19, no. 1, pp. 20-28, 2001.

[84] M. J. Coelho, A. Trigo Cabral, and M. H. Fernandes, "Human bone cell cultures in biocompatibility testing. Part I: osteoblastic differentiation of serially passaged human bone marrow cells cultured in $\alpha$-MEM and in DMEM," Biomaterials, vol. 21, no. 11, pp. 1087-1094, 2000.

[85] F. Sugiura, H. Kitoh, and N. Ishiguro, "Osteogenic potential of rat mesenchymal stem cells after several passages," Biochemical and Biophysical Research Communications, vol. 316, no. 1, pp. 233-239, 2004.

[86] Y. Shikinami, K. Okazaki, M. Saito et al., "Bioactive and bioresorbable cellular cubic-composite scaffolds for use in bone reconstruction," Journal of the Royal Society Interface, vol. 3, no. 11, pp. 805-821, 2006.

[87] L. Liu, W. Yuan, and J. Wang, "Mechanisms for osteogenic differentiation of human mesenchymal stem cells induced by fluid shear stress," Biomechanics and Modeling in Mechanobiology, vol. 9, no. 6, pp. 659-670, 2010.

[88] J. Y. Lim, A. E. Loiselle, J. S. Lee, Y. Zhang, J. D. Salvi, and H. J. Donahue, "Optimizing the osteogenic potential of adult stem cells for skeletal regeneration," Journal of Orthopaedic Research, vol. 29, no. 11, pp. 1627-1633, 2011.

[89] G. Chamberlain, J. Fox, B. Ashton, and J. Middleton, "Concise review: mesenchymal stem cells: their phenotype, 
differentiation capacity, immunological features, and potential for homing," Stem Cells, vol. 25, no. 11, pp. 2739-2749, 2007.

[90] B. M. Hall, S. Dorsch, and B. Roser, "The cellular basis of allograft rejection in vivo. I. The cellular requirements for first-set rejection of heart grafts," Journal of Experimental Medicine, vol. 148, no. 4, pp. 878-889, 1978.

[91] E. H. Javazon, K. J. Beggs, and A. W. Flake, "Mesenchymal stem cells: paradoxes of passaging," Experimental Hematology, vol. 32, no. 5, pp. 414-425, 2004.

[92] A. Bartholomew, C. Sturgeon, M. Siatskas et al., "Mesenchymal stem cells suppress lymphocyte proliferation in vitro and prolong skin graft survival in vivo," Experimental Hematology, vol. 30, no. 1, pp. 42-48, 2002.

[93] M. D. Nicola, C. Carlo-Stella, M. Magni et al., "Human bone marrow stromal cells suppress T-lymphocyte proliferation induced by cellular or nonspecific mitogenic stimuli," Blood, vol. 99, no. 10, pp. 3838-3843, 2002.

[94] O. Delarosa, E. Lombardo, A. Beraza et al., "Requirement of IFN- $\gamma$-mediated indoleamine 2,3-dioxygenase expression in the modulation of lymphocyte proliferation by human adipose-derived stem cells," Tissue Engineering A, vol. 15, no. 10, pp. 2795-2806, 2009.

[95] J. M. Ryan, F. Barry, J. M. Murphy, and B. P. Mahon, "Interferon- $\gamma$ does not break, but promotes the immunosuppressive capacity of adult human mesenchymal stem cells," Clinical and Experimental Immunology, vol. 149, no. 2, pp. 353-363, 2007.

[96] A. Corcione, F. Benvenuto, E. Ferretti et al., "Human mesenchymal stem cells modulate B-cell functions," Blood, vol. 107, no. 1, pp. 367-372, 2006.

[97] S. Asari, S. Itakura, K. Ferreri et al., "Mesenchymal stem cells suppress B-cell terminal differentiation," Experimental Hematology, vol. 37, no. 5, pp. 604-615, 2009.

[98] R. Ramasamy, H. Fazekasova, E. W. F. Lam, I. Soeiro, G. Lombardi, and F. Dazzi, "Mesenchymal stem cells inhibit dendritic cell differentiation and function by preventing entry into the cell cycle," Transplantation, vol. 83, no. 1, pp. 71-76, 2007.

[99] W. Zhang, W. Ge, C. Li et al., "Effects of mesenchymal stem cells on differentiation, maturation, and function of human monocyte-derived dendritic cells," Stem Cells and Development, vol. 13, no. 3, pp. 263-271, 2004.

[100] H. M. Lazarus, O. N. Koc, S. M. Devine et al., "Cotransplantation of HLA-identical sibling culture-expanded mesenchymal stem cells and hematopoietic stem cells in hematologic malignancy patients," Biology of Blood and Marrow Transplantation, vol. 11, no. 5, pp. 389-398, 2005.

[101] K. Le Blanc, I. Rasmusson, B. Sundberg et al., "Treatment of severe acute graft-versus-host disease with third party haploidentical mesenchymal stem cells," Lancet, vol. 363, no. 9419, pp. 1439-1441, 2004.

[102] J. M. Fox, G. Chamberlain, B. A. Ashton, and J. Middleton, "Recent advances into the understanding of mesenchymal stem cell trafficking," British Journal of Haematology, vol. 137, no. 6, pp. 491-502, 2007.

[103] F. Granero-Moltó, J. A. Weis, M. I. Miga et al., "Regenerative effects of transplanted mesenchymal stem cells in fracture healing," Stem Cells, vol. 27, no. 8, pp. 1887-1898, 2009.

[104] F. Granero-Molto, J. A. Weis, L. Longobardi, and A. Spagnoli, "Role of mesenchymal stem cells in regenerative medicine: application to bone and cartilage repair," Expert Opinion on Biological Therapy, vol. 8, no. 3, pp. 255-268, 2008.
[105] T. Lapidot, A. Dar, and O. Kollet, "How do stem cells find their way home?” Blood, vol. 106, no. 6, pp. 1901-1910, 2005.

[106] T. Kitaori, H. Ito, E. M. Schwarz et al., "Stromal cell-derived factor 1/CXCR4 signaling is critical for the recruitment of mesenchymal stem cells to the fracture site during skeletal repair in a mouse model," Arthritis and Rheumatism, vol. 60, no. 3, pp. 813-823, 2009.

[107] E. M. Horwitz, P. L. Gordon, W. K. K. Koo et al., "Isolated allogeneic bone marrow-derived mesenchymal cells engraft and stimulate growth in children with osteogenesis imperfecta: Implications for cell therapy of bone," Proceedings of the National Academy of Sciences of the United States of America, vol. 99, no. 13, pp. 8932-8937, 2002.

[108] D. Gazit, G. Turgeman, P. Kelley et al., "Engineered pluripotent mesenchymal cells integrate and differentiate in regenerating bone: a novel cell-mediated gene therapy," Journal of Gene Medicine, vol. 1, no. 2, pp. 121-133, 1999.

[109] J. R. Lieberman, A. Daluiski, and T. A. Einhorn, "The role of growth factors in the repair of bone biology and clinical applications," Journal of Bone and Joint Surgery A, vol. 84, no. 6, pp. 1032-1044, 2002.

[110] B. C. Carofino and J. R. Lieberman, "Gene therapy applications for fracture-healing," Journal of Bone and Joint Surgery A, vol. 90, supplement 1, pp. 99-110, 2008.

[111] D. S. Musgrave, P. Bosch, S. Ghivizzani, P. D. Robbins, C. H. Evans, and J. Huard, "Adenovirus-mediated direct gene therapy with bone morphogenetic protein-2 produces bone," Bone, vol. 24, no. 6, pp. 541-547, 1999.

[112] J. Park, J. Ries, K. Gelse et al., "Bone regeneration in critical size defects by cell-mediated BMP-2 gene transfer: a comparison of adenoviral vectors and liposomes," Gene Therapy, vol. 10, no. 13, pp. 1089-1098, 2003.

[113] S. C. Gamradt and J. R. Lieberman, "Genetic modification of stem cells to enhance bone repair," Annals of Biomedical Engineering, vol. 32, no. 1, pp. 136-147, 2004.

[114] D. Hong, H. X. Chen, R. Ge, and J. C. Li, "Genetically engineered mesenchymal stem cells: the ongoing research for bone tissue engineering," Anatomical Record, vol. 293, no. 3, pp. 531-537, 2010.

[115] J. R. Lieberman, A. Daluiski, S. Stevenson et al., "The effect of regional gene therapy with bone morphogenetic protein2- producing bone-marrow cells on the repair of segmental femoral defects in rats," Journal of Bone and Joint Surgery A, vol. 81, no. 7, pp. 905-917, 1999.

[116] K. D. Riew, N. M. Wright, S. L. Cheng, L. V. Avioli, and J. Lou, "Induction of bone formation using a recombinant adenoviral vector carrying the human BMP-2 gene in a rabbit spinal fusion model," Calcified Tissue International, vol. 63, no. 4, pp. 357-360, 1998.

[117] R. Gysin, J. E. Wergedal, M. H. C. Sheng et al., "Ex vivo gene therapy with stromal cells transduced with a retroviral vector containing the BMP4 gene completely heals critical size calvarial defect in rats," Gene Therapy, vol. 9, no. 15, pp. 991-999, 2002.

[118] L. Lin, Q. Shen, X. Wei et al., "Comparison of osteogenic potentials of BMP4 transduced stem cells from autologous bone marrow and Fat tissue in a rabbit model of calvarial defects," Calcified Tissue International, vol. 85, no. 1, pp. 5565, 2009.

[119] Z. Zhao, Z. Wang, C. Ge, P. Krebsbach, and R. T. Franceschi, "Healing cranial defects with AdRunx2-transduced marrow stromal cells," Journal of Dental Research, vol. 86, no. 12, pp. 1207-1211, 2007. 
[120] S. Yang, D. Wei, D. Wang, M. Phimphilai, P. H. Krebsbach, and R. T. Franceschi, "In vitro and in vivo synergistic interactions between the Runx2/Cbfa1 transcription factor and bone morphogenetic protein-2 in stimulating osteoblast differentiation," Journal of Bone and Mineral Research, vol. 18, no. 4, pp. 705-715, 2003. 

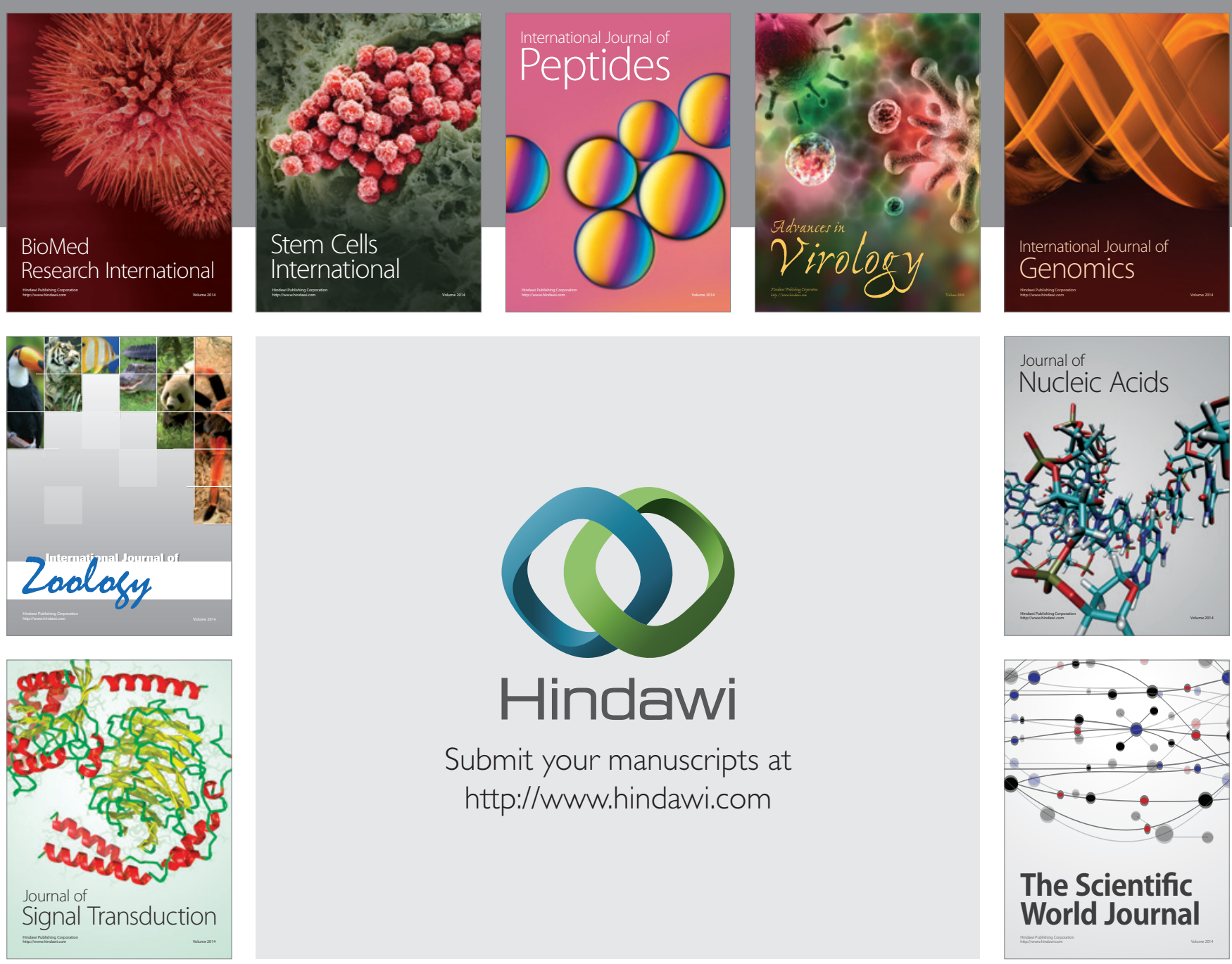

Submit your manuscripts at

http://www.hindawi.com
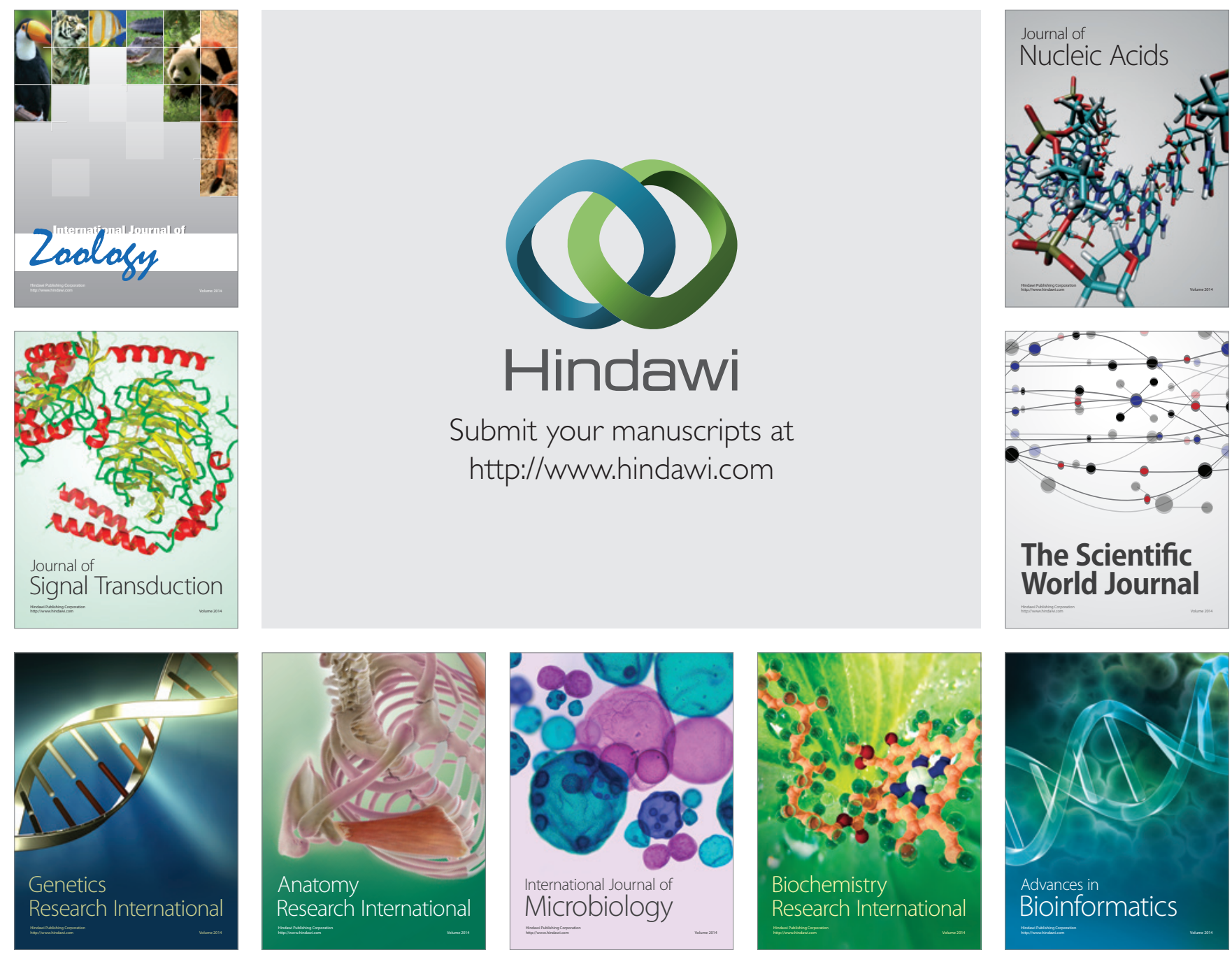

The Scientific World Journal
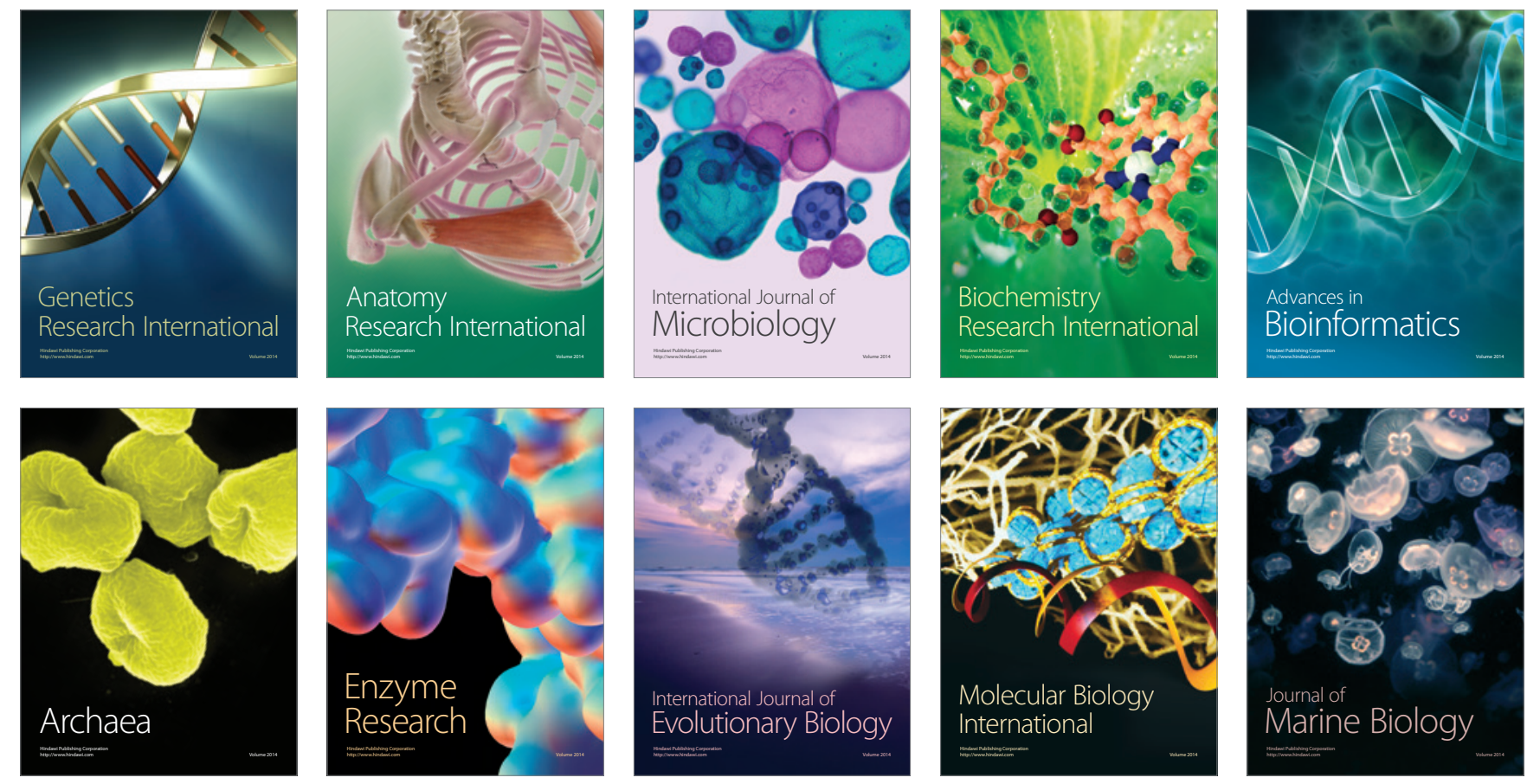